\title{
A Through-Process Experimental Approach to Enable Optimization of Cold Sprayed Al 7075 Consolidation Performance
}

\author{
KYLE TSAKNOPOULOS ${ }^{10},{ }^{1,3}$ BRYER SOUSA, ${ }^{1}$ CHRISTOPHER MASSAR, ${ }^{1}$ \\ JACK GRUBBS, ${ }^{1}$ MATHEW SIOPIS, ${ }^{2}$ and DANIELLE COTE ${ }^{1}$
}

1.-Worcester Polytechnic Institute, Worcester, MA, USA. 2.-US Army Research Laboratory, Aberdeen Proving Grounds, Aberdeen, MD, USA. 3.—e-mail: kltsaknopoulos@wpi.edu

\begin{abstract}
This work employs an example of a through process experiment systematic approach to study the relationship among powder properties, cold spray (CS) processing parameters, and consolidated specimen behavior through a combined effort of characterization methods and computational models. This process will allow for the systematic isolation of variables that can affect powder and CS deposit properties. In this study, $\mathrm{Al} 7075$ powder was used as feedstock to produce a CS coating using industry-standard processing parameters. Techniques such as SEM, EDS, XRD, nanoindentation, and tensile testing were used to characterize the properties of both the feedstock powder and CS deposits. In addition, computational thermodynamic modeling was used to guide the interpretation of microstructural features of the powder and CS specimen. Finally, an additive yield strength model was employed to quantify the strengthening components introduced through the CS process.
\end{abstract}

\section{INTRODUCTION}

Cold spray (CS) is a solid-state consolidation technology that produces functional metallic and non-metallic deposits and near-net consolidations. ${ }^{1}$ CS consolidations have been shown to attain wrought-like properties when processed using optimized parameters and post-CS processing techniques. ${ }^{2}$ This processing avoids many deleterious and thermally mediated aspects associated with elevated temperature coating deposition methods (arc, plasma, and flame spraying). ${ }^{3}$ CS allows for restoration of damaged components, ${ }^{4}$ the reinforcement of components that incurred in-field and usage-based wear zones, ${ }^{5}$ and the application of superior materials onto critical areas of a respective target specimen, which could not otherwise be achieved by way of subtractive processing and manufacturing. ${ }^{6}$

(Received April 12, 2021; accepted October 25, 2021; published online November 19, 2021)
CS processing uses microparticulate feedstock, ${ }^{7}$ typically metallic powders of a size range of 10 $100 \mu \mathrm{m}$ that are traditionally fed into an inert carrier gas stream until reaching a convergingdiverging nozzle. This nozzle geometry allows the particulates to be accelerated to supersonic velocities towards a respective substrate or uncoated specimen. ${ }^{8}$ Particles that reach a sufficient critical impact velocity plastically deform upon contact such that solid-state metallurgical and mechanical bonding occurs between the substrate, the particles, and the already deposited layers until a layer-by-layer build of the desired dimensionality is achieved. ${ }^{9}$

When appropriately modeled and optimized through guided experimentation, such as those presented herein, CS consolidation creates coatings with effectively full densification ${ }^{10}$ and a relatively high coating-substrate bond strength. ${ }^{11}$ In addition, $\mathrm{CS}$ is unique compared to other coatings technologies in that temperatures are maintained below the melting point of the feedstock material used; accordingly, the feedstock powder remains in the solidstate during the CS process. As a result, the powder's properties and microstructure are retained and dynamically recrystallized in the final CS 
material, ${ }^{11,12}$ thus enabling tunable performance. Such tunability has resulted in CS material joining with tensile residual stress-free zones within the welded region, wear-resistant coatings with extended lifetimes, and maritime structural restorations with corrosion resistance.

Industrially speaking, Al 7075 has maintained widespread use within the aerospace and aircraft manufacturing sectors as structural components capable of operating in mechanically stressful environments. ${ }^{13} \mathrm{Al} 7075 \mathrm{CS}$ coatings and consolidations have been under development for more than a decade. $^{14}$ Interest in Al $7075 \mathrm{CS}$ feedstock has mainly been concerned with the alloy's use as a coating for corrosion resistance of $\mathrm{Mg}$ alloys and other materials of relevance to the aerospace and defense sectors. ${ }^{15}$ Beyond corrosion resistance, $\mathrm{Al}$ 7075 CS has been used for non-structural repair of decommissioned aerospace components. ${ }^{16}$ Other uses of $\mathrm{Al} 7075$ in $\mathrm{CS}$ applications have been reported, too; ${ }^{17}$ however, universal structural applicability has yet to be fully reached. ${ }^{18}$ The drive for structural applications using Al 7075 CS processing was one of many motivations for the research presented here. The properties and performance of Al 7075 are owed primarily to the microstructural constituents present, which exist as a function of the respective temper (worked condition or heattreated state). Several potential precipitation sequences may occur, depending on the exact alloy composition and local concentrations of elements within the material. $\mathrm{Al}_{2} \mathrm{CuMg}$ (S-phase), $\mathrm{Al}_{2} \mathrm{Mg}_{3} \mathrm{Zn}_{3}$ (T-phase), and $\operatorname{MgZn} 2(\eta)$ may be the predominant equilibrium phases whose precursors include $T^{\prime}$ and $\eta^{\prime}$.

Many variables affect the final properties of CS consolidations and can be broken into two main categories: spray parameters and powder properties. CS parameters include the selection of applicator, nozzle type, size, configuration, gas type, temperature, and pressure. Primary powder variables affecting CS include particle size, morphology, flowability, chemistry, heat treatment, and the resultant hardness and modulus of the feedstock. ${ }^{19,20}$ Many of these variables must be controlled and optimized for different application types and materials. For example, powder size can be controlled through mechanical sieving to the desired size. Powder morphology is generally managed through the choice of a powder manufacturing process. For example, atomization produces powders that are generally more spherical compared to powders produced by ball milling, water atomization, or other mechanical techniques. Powder chemistry is chosen based on application-driven demand. Finally, powder heat treatment controls powder properties and microstructures to enhance sprayability and final CS properties. ${ }^{21,22}$
Returning to the matter of CS processing parameters classified under the umbrella of spray parameters (vs. powder properties) in relation to their respective influence upon the resultant consolidated material properties and performance, prior work has found that $\mathrm{CS}$ processed $\mathrm{Al}$ alloy feedstocks and $\mathrm{Al}$ alloy substrate combinations maintained increased compressive residual stress states as carrier gas pressure increased and decreased compressive residual stress states as carrier gas temperature decreased. As a result of the sensitivity of the compressive residual stress state to processing gas pressure and gas temperature, the fatigue resistance could be tuned via higher pressures for improved mechanical performance. Furthermore, one may consider the influence of spray parameters upon CS processed coating densities, such as standoff distance, carrier gas temperature, carrier gas pressure, and method of powder feeding. Accordingly, one may further relate the coating density to yield strength, hardness, and ductility of CS consolidated materials.

To maximize the benefits of CS processing, a through-process model (TPM) was developed to predict CS-processed material properties as a function of feedstock properties and processing parameters. However, the synergy between modeling and experimentation remains crucial in developing the TPM further. Therefore, the purpose of the Through Process Experiment (TPE) presented as an initial demonstrative study herein was to pilot the creation of a systematic approach to study the relationship between powder properties and consolidated CS behavior through a combined effort of characterization methods guided by computational thermodynamic models for all stages of the TPM. More specifically, the present study aims to tailor the mechanical properties of consolidated Al 7075 CS deposits through powder heat treatment and strict control of processing variables, aided by advanced characterization and modeling techniques.

\section{METHODS}

\section{Through-Process Experimentation}

The approach of the TPE presented in this work is designed to allow for the systematic isolation of variables that affect both powder and CS properties. This is realized by controlling powder thermal treatments and manipulating CS processing parameters, as outlined in Fig. 1.

\section{Powder}

Gas-atomized Al 7075 powder was used herein and obtained from Solvus Global (Worcester, MA). Solvus Global reported the third-party tested chemical composition of the powder as 0.24 wt.\% $\mathrm{Cr}$, 1.54 wt.\% $\mathrm{Cu}, 0.13$ wt.\% $\mathrm{Fe}, 2.13$ wt.\% $\mathrm{Mg}$, 0.08 wt.\% Si, 0.01 wt.\% Ti, and 5.34 wt.\% $\mathrm{Zn}$, and 


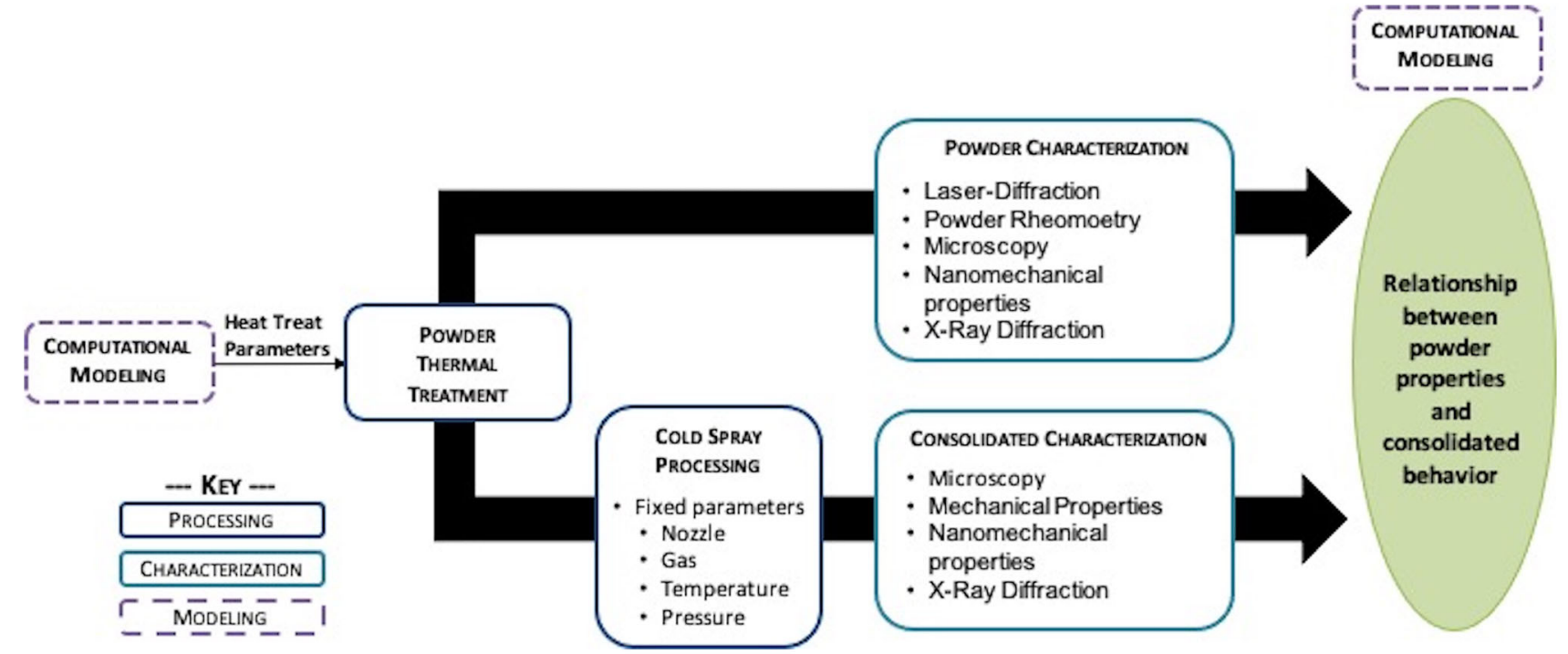

Fig. 1. Schematic of the TPE.

balanced by $\mathrm{Al}$, which was within specified chemistry limits defined by the Aluminum Association. The vendor heat-treated the powder using a proprietary treatment between $200^{\circ} \mathrm{C}$ and $300^{\circ} \mathrm{C}$ for approximately $1 \mathrm{~h}$.

\section{Cold Spray Parameters}

An Al 6061-T651 wrought plate from Online Metals (Seattle, WA) was utilized as the substrate, given the regular occurrence of depositing $\mathrm{Al} 7075$ powder feedstock onto $\mathrm{Al}$ 6061-T651. ${ }^{23} \mathrm{An}$ automated VRC Metals Systems GEN III high-pressure CS system (Box Elder, SD) was used for consolidation. CS processing was performed at the Cold Spray Synergy Site (Webster, MA), wherein the system was equipped with a polybenzimidazole (PBI) nozzle. The PBI nozzle, identified as Nozzle \#0071, had a throat diameter of $1.75 \mathrm{~mm}$, an exit diameter of $5 \mathrm{~mm}$, and an overall length of $170 \mathrm{~mm}$, with a diverging length of approximately $152 \mathrm{~mm}$. The deposition was performed on the Al 6061-T651 substrate at a $25-\mathrm{mm}$ standoff distance, $200 \mathrm{~mm} / \mathrm{s}$ gun speed, and 1-mm step size, yielding a deposit with a thickness of $4.826 \mathrm{~mm}$. The carrier gas was pure $\mathrm{He}$, the spray angle was orthogonal to the substrate, the applicator type used was a block applicator, the applicator set temperature was $445^{\circ} \mathrm{C}$, the system pressure was $535 \mathrm{psi}$, the powder feeder rate was 4.0 RPM, and the powder feeder flow rate was $120 \mathrm{slm}$. Finally, the surface of the Al 6061-T651 substrate was activated prior to spraying by way of a wire grinder/brush wheel with alcohol.

\section{Characterization}

Particle size distribution and morphology were characterized using a Microtrac FlowSync system (Microtrac Retsch GmbH, Haan/Duesseldorf, Germany). Powder and CS samples were mounted in a phenolic resin using a Buehler Simplimet 4000 (Lake Bluff, IL) compression mounting system for scanning electron microscopy (SEM) and characterization. Grinding and polishing were completed using a Buehler Ecomet 300 automatic polisher until a final mirror finish was reached with a $0.02 \mu \mathrm{m}$ colloidal silica suspension. Powder samples were also ion-mill polished using argon gas in a JEOL IB-19530CP cross-section polisher (Tokyo, Japan) for improved SEM micrograph quality. Milling was performed at $8 \mathrm{kV}$ for $3 \mathrm{~h}$ with an intermittent polish procedure of $5 \mathrm{~s}$ on and $5 \mathrm{~s}$ off.

Powder rheology experiments were performed using a Revolution Powder Analyzer (RPA) from Mercury Scientific Inc. (Newtown, CT). The RPA utilizes high-speed imaging to capture a powder's flow behavior upon rotation in a cylindrical drum, whereby "avalanches" of the powder (not particle) surface occur. The "Flow" method was used such that the powder was rotated in a 25-cc drum at $0.3 \mathrm{rpm}$ until 110 total avalanches occurred; the data from the 100 centermost avalanches in the set were utilized for analysis. In addition, thousands of images were taken during the 110 avalanches, indicating the statistical significance of the flow data collected.

A Zeiss EVO MA10 (Carl Zeiss AG, Oberkochen, Germany) SEM was used to obtain micrographs of powder and CS deposit internal microstructures. A Bruker X Flash Energy-Dispersive Spectroscopy (EDS) Detector 630M (Bruker Nano GmbH, Berlin Germany) was used to map samples chemically. Image analysis software, Olympus Stream, was used for grain size and secondary phase analysis of SEM micrographs using a contrast thresholding approach previously used elsewhere. ${ }^{19}$ X-ray diffraction (XRD) was conducted on powder and CS samples using an Empyrean X-ray Diffractometer (Malvern Panalytical Ltd., Almelo, Overijssel, 
Netherlands), a $\mathrm{Cu}-\mathrm{K} \alpha$ radiation source, and $\mathrm{Ni}$ filter. Data analysis was completed using the HighScore Plus software.

Nanoindentation was performed using an iMicro Pro from the KLA Corp. (Milpitas, CA) on metallographically prepared powder particles. An InForce $1000 \mathrm{mN}$ actuator was employed with a diamond Berkovich tip from Micro Star Technologies Inc. (Huntsville, TX) and operated using the InView Software program (Version 19.2.24). Twenty-five particles were tested; however, only 16 load-displacement curves were retained, given the need for adequately placed indents. Nanoindentation hardness measurements were reported at depths averaging between $195 \mathrm{~nm}$ and $205 \mathrm{~nm}$ using a dynamic method. The contact area function and the frame stiffness were first analytically determined via loaddepth data obtained from a fused silica reference standard. Thermal drift, pile-up, and creep-related phenomena were corrected during testing. For additional information regarding nanoindentation testing for particulate feedstock, consider. ${ }^{24}$ Nanomechanical mapping and k-means clustering were also applied to the present work for deformation structure analysis.

Uniaxial tensile testing was completed using an Instron (Norwood, MA) Model 1127 and following ASTM E8/EM8-21. ${ }^{25}$ Only samples that broke within the gauge length were considered during analysis. Extensometer data were captured using a static 2630-108 transducer designed for a sub-sized specimen with a 1-inch gauge length. The data were captured and analyzed using the Bluehill software package. These samples were prepared by removing the Al 6061-T561 substrate from the consolidated deposit and machining the as-deposited surface to a flatness of \pm 0.0005 inches. Water jetting was employed to fabricate the tensile coupons at Central MA Waterjet, Inc. (Millbury, MA).

\section{Modeling}

Thermo-Calc (Stockholm, Sweden), a computational thermodynamic and kinetic software, was used to guide characterization by predicting the potential secondary phases present in the microstructures of the powder feedstock and thus CS deposit. In addition, the TCAL7 database was used to create equilibrium and non-equilibrium Scheil solidification diagrams to predict secondary phases.

\section{RESULTS AND DISCUSSION}

\section{Powder}

The size and morphology of the $\mathrm{Al} 7075$ feedstock were explored through SEM analysis and quantified via a particle size and shape analyzer. Figure 2a presents SEM micrographs of the as-received powder. Figure $2 \mathrm{a}$ revealed that the gas-atomized powder was mostly spherical with smaller satellites

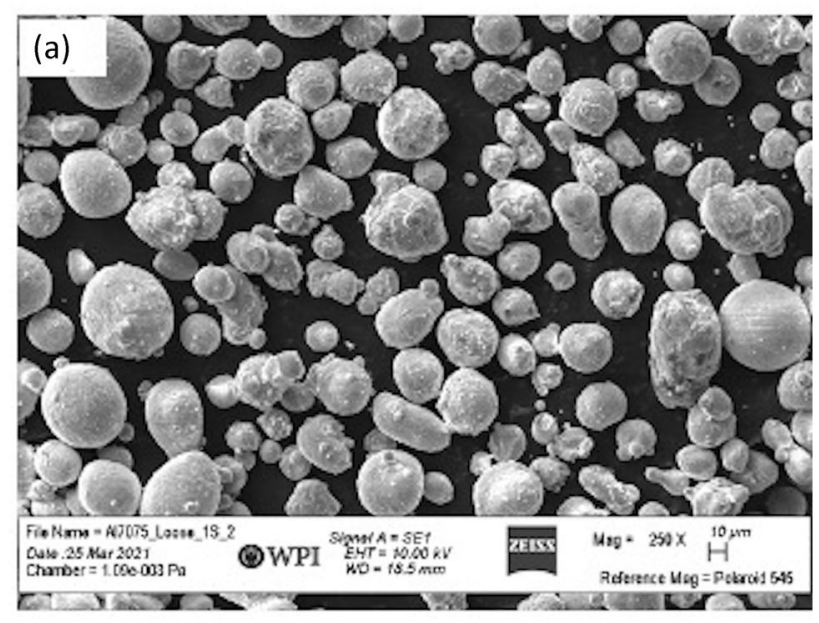

(b)

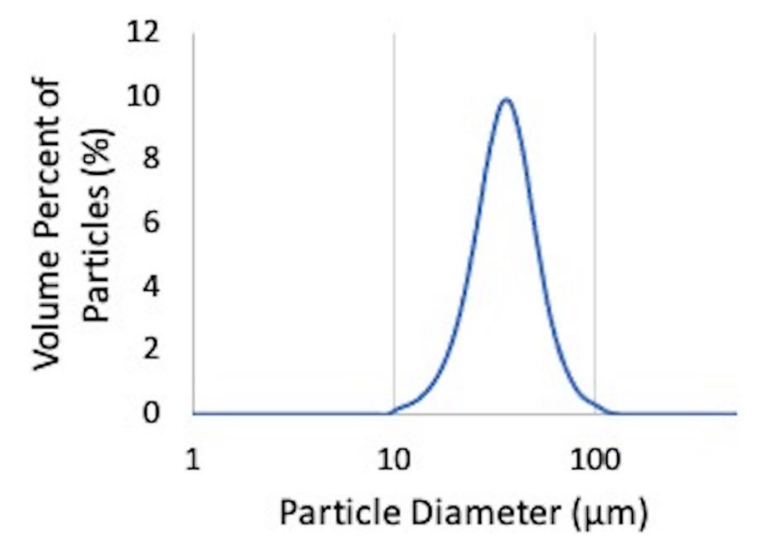

Fig. 2. (a) SEM micrograph and (b) particle size distribution of the Al 7075 feedstock powder.

on the surface. Figure $2 \mathrm{~b}$ demonstrates the powders' size distribution, with a $D_{10}, D_{50}$, and $D_{90}$ of $20.68 \mu \mathrm{m}, 33.77 \mu \mathrm{m}$, and $53.44 \mu \mathrm{m}$, respectively. Analysis of the particle morphologies revealed an average particle width-to-length ratio of 0.792 ; this was consistent with the qualitative and SEM-based observation that most particles are spherical or slightly oblong, with several particles containing small satellite particles on their surface.

Powder rheology was leveraged to measure the flowability of the $\mathrm{Al} 7075$ powder. Upon testing the powder with the "Flow" method of the RPA, two key parameters were deemed necessary: the SL ratio and the avalanche angle. These parameters describe a different feature of the powder flow behavior, which can allow a powder sample to be screened for use in CS. ${ }^{26}$ The SL ratio, or the solidliquid ratio, is a unitless parameter between 0 and 1 , indicating whether the powder acts more like a solid (value of 1 ) or liquid (value of 0 ) in a dynamic environment. For this powder, the average SL ratio was 0.39 , suggesting that the powder has more liquid-like behavior, which may be beneficial for CS, as the powder must flow freely from the powder 
feeder to the applicator. The avalanche angle reported is also a robust metric related to powder flowability. This angle is the point at which an avalanche occurs while the drum of powder is rotating; the lower the avalanche angle, the better the powder flowability is. Here, the average avalanche angle was $45.1^{\circ} \pm 3^{\circ}$, which is a relatively standard value for metallic powders. The moderate avalanche angle combined with the low SL ratio demonstrates that the $\mathrm{Al} 7075$ powder has acceptable flow characteristics for the CS process.

Figure 3 presents SEM micrographs and EDS mapping of the cross-sectionally polished feedstock. Figure $3 \mathrm{a}$ and $\mathrm{b}$ shows secondary and backscatter micrographs of the internal powder microstructure. Image analysis measured an average grain size of $1.77 \mu \mathrm{m} \pm 0.20 \mu \mathrm{m}$. Both the secondary and backscatter powder images show bright contrasting phases at the grain boundaries and some small, nucleated phases inside the bulk of the grain. Figure $3 \mathrm{c}$ shows elemental EDS maps of the internal powder microstructure. Elemental segregation of $\mathrm{Mg}, \mathrm{Zn}$, and $\mathrm{Cu}$ to the grain boundaries suggests that the bright contrast at the boundaries could be a $\mathrm{MgZnCu}$ phase, such as a form of T-phase, as noted within $\mathrm{Al} 7075$ powders reported elsewhere ${ }^{19,27,28}$ and shown to be dependent upon quaternary ratios of $\mathrm{Al}-\mathrm{Zn}-\mathrm{Cu}-\mathrm{Mg}{ }^{29}$

To further investigate the internal particulate microstructures, thermodynamic modeling was used to interpret potentially present phases within the powder as a function of thermal treatment applied. Figure 4a demonstrates the non-equilibrium Scheil solidification diagram for this powder composition. This diagram is generally helpful when interpreting the microstructure of as-atomized powder particles, as the atomization process involves rapid solidification, where Scheil is valid. ${ }^{28,30-32}$ The most abundant phase present in the Scheil prediction was the Tphase, with a volume percentage of $3.2 \%$.

Figure $4 \mathrm{~b}$ presents the thermodynamic equilibrium diagram calculated for this chemical composition, which can help interpret microstructures as a function of thermal treatment. The present powder was heat-treated at a temperature between $200^{\circ} \mathrm{C}$ and $300^{\circ} \mathrm{C}$, where the most abundant phase predicted to be present in the microstructure was the Tphase, with a volume percentage of $6.6 \%$. All additionally predicted phases for both Scheil and equilibrium calculations were predicted to have a volume percentage $<0.8 \%$ and will be studied in greater detail during follow-on work. Thus, the volume percentage of T-phase associated with the thermodynamic phase equilibrium diagram computed for the specific powder chemistry compliments the T-phase indications that followed from EDS and Scheil analysis.

Figure 5 shows the XRD spectra for the feedstock powder. The XRD spectrum confirmed the presence
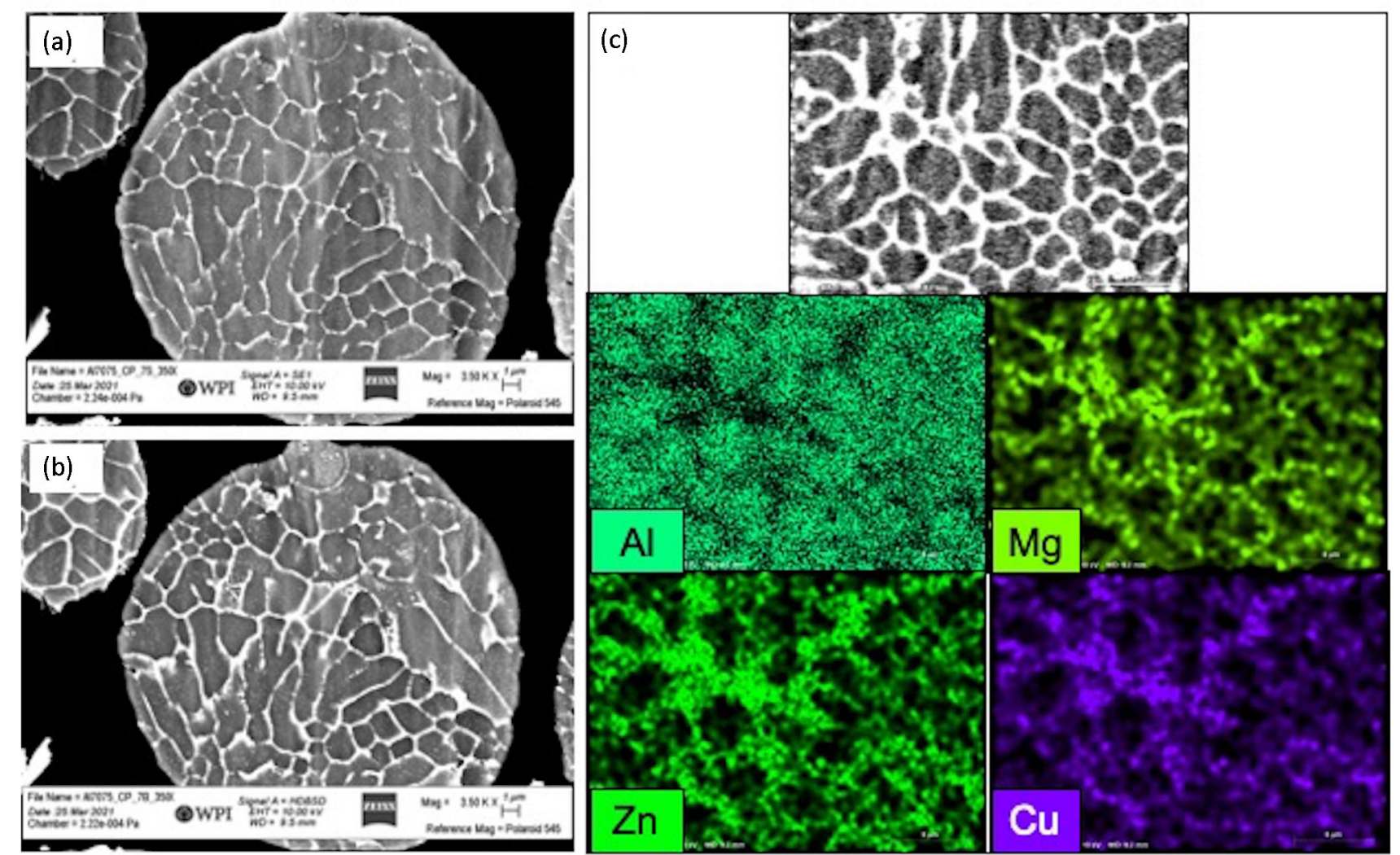

Fig. 3. SEM micrographs of cross-sectioned Al 7075 feedstock powder using (a) secondary imaging, (b) backscatter imaging, and (c) EDS elemental mapping for $\mathrm{Al}, \mathrm{Mg}, \mathrm{Zn}$, and $\mathrm{Cu}$. 
(a)

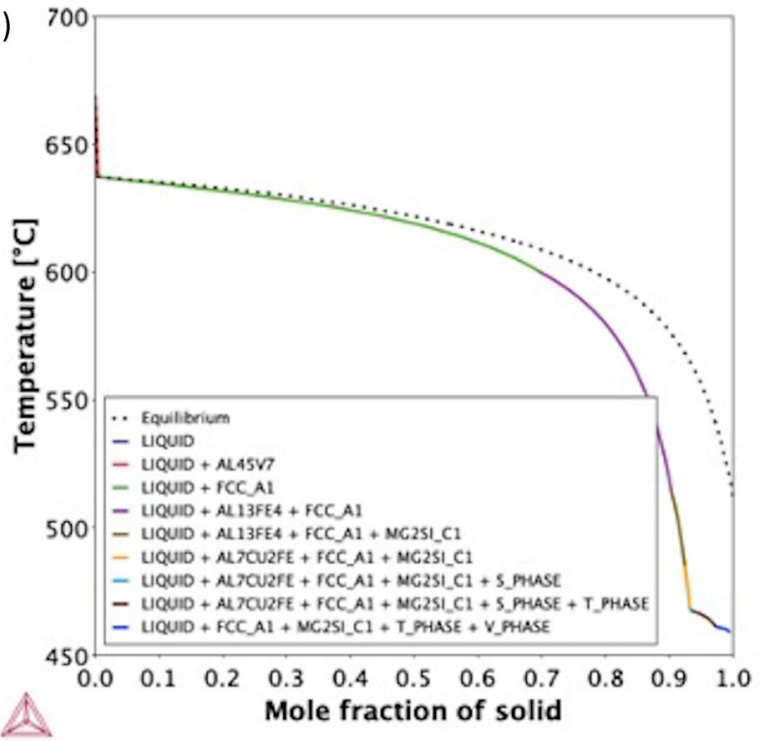

(b)

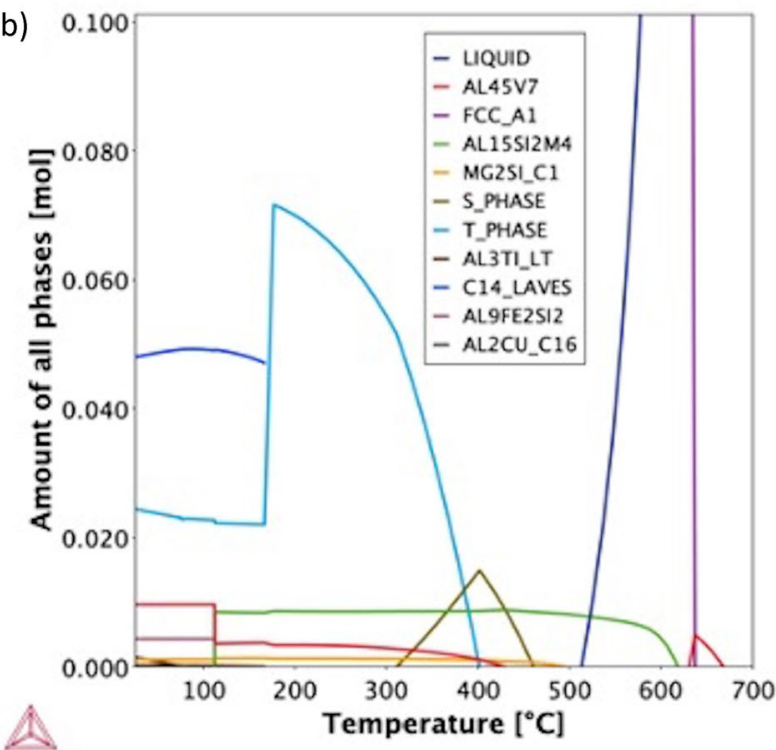

Fig. 4. (a) Non-equilibrium Scheil solidification diagram and (b) equilibrium diagram, as calculated by Thermo-Calc.

of T-phase $\left(\mathrm{Al}_{2} \mathrm{Mg}_{3} \mathrm{Zn}_{3}\right)$. T-phase can also substitute $\mathrm{Cu}$ into the lattice (as was determined through Thermo-Calc), which was likely the case herein as $\mathrm{Cu}$ segregation to the grain boundaries was seen in Fig. 3c. Image analysis of the secondary phases present at the powder particle grain boundaries in the SEM micrographs (Fig. 3a) revealed a phase fraction of $10.82 \% \pm 2.25 \%$. Assuming that all the secondary phases at the boundaries are indeed Tphase, this value was higher than that predicted by Thermo-Calc for the amount of T-phase present at the heat treatment temperature. This is likely due to the excessively bright contrasting phase at the boundaries in the SEM micrographs.
Relative phase fractions for the $\mathrm{Al} 7075$ powder considered in Ref 19 were like those reported in the present study. It is possible that the composition of the matrix could have a slightly different local equilibrium, which could also lead to an increase in the amount of T-phase present, thus serving to substantiate the complimentary work reported in Ref 19. This phase fraction value suggests that the powder should be at a state close to equilibrium. Since this powder did not undergo a solutionization treatment before heat treatment, some T-phase was likely present from the initial atomization process (as predicted by the Scheil solidification calculation). Upon heat treatment, the T-phase at the boundary would coarsen and nucleate new T-phase in the bulk of the grains, as seen in Fig. 3a.

Considering the significance of powder microstructure upon mechanical properties and mechanical properties upon impact deformation behavior, nanoindentation was utilized to measure powder hardness and modulus, reported at $1.55 \mathrm{GPa}$ and $71.71 \mathrm{GPa}$, respectively. Additional nano-to-microscale indentation data are presented in Fig. $6 \mathrm{~b}$ in terms of the hardness as a function of indentation depth for the various orientations of the CS processed consolidations relative to the spray direction.

\section{Cold Spray}

Relative to the deposition efficiencies (DEs) typically associated with $\mathrm{CS}$ processed pure $\mathrm{Al}$ and aluminum alloys such as Al 6061 (when processed using optimal processing parameters), ${ }^{33} \mathrm{Al} 7075$ and $\mathrm{Al} 2024$ gas-atomized powders have previously been found to have notably low DE in comparison. For example, previous researchers have reported $\mathrm{DEs}$ for as atomized and thermally pre-processed $\mathrm{Al}$ 7075 feedstock of only 5\%, 10\%, and $25 \%$ in Ref. 34 . That said, the DE measured during the present research was $58.1 \%$, which significantly exceeds the DEs recorded by Sabard et al. In comparison with the work of Story ${ }^{35}$ which reported DEs just shy of 80\% when the $\mathrm{Al} 7075$ powder was processed using He gas and deposited onto an Al 7075-T651 substrate, the relatively lesser DE measured by the present authors can be explained in terms of the difference between the substrates utilized. Story deposited $\mathrm{Al} 7075$ feedstock onto an Al 7075 substrate vs. the fact that the current authors deposited $\mathrm{Al} 7075$ feedstock onto an $\mathrm{Al} 6061$ substrate system. Variation in CS processing parameters, pre-processing of Al 7075 feedstock, and Story's deposition of like-on-like $\mathrm{Al} 7075$ onto $\mathrm{Al} 7075$ substrates ultimately underpin the difference in $\mathrm{DE}$ calculated in the present work and the DE identified by Story. With this baseline DE of $58 \%$, this metric will be considered in the future during the design of processing parameters and powder conditioning to obtain idealized DE, ductility, and strength. Meanwhile, microscopy, mechanical characterization, and 
A Through-Process Experimental Approach to Enable Optimization of Cold Sprayed Al 7075

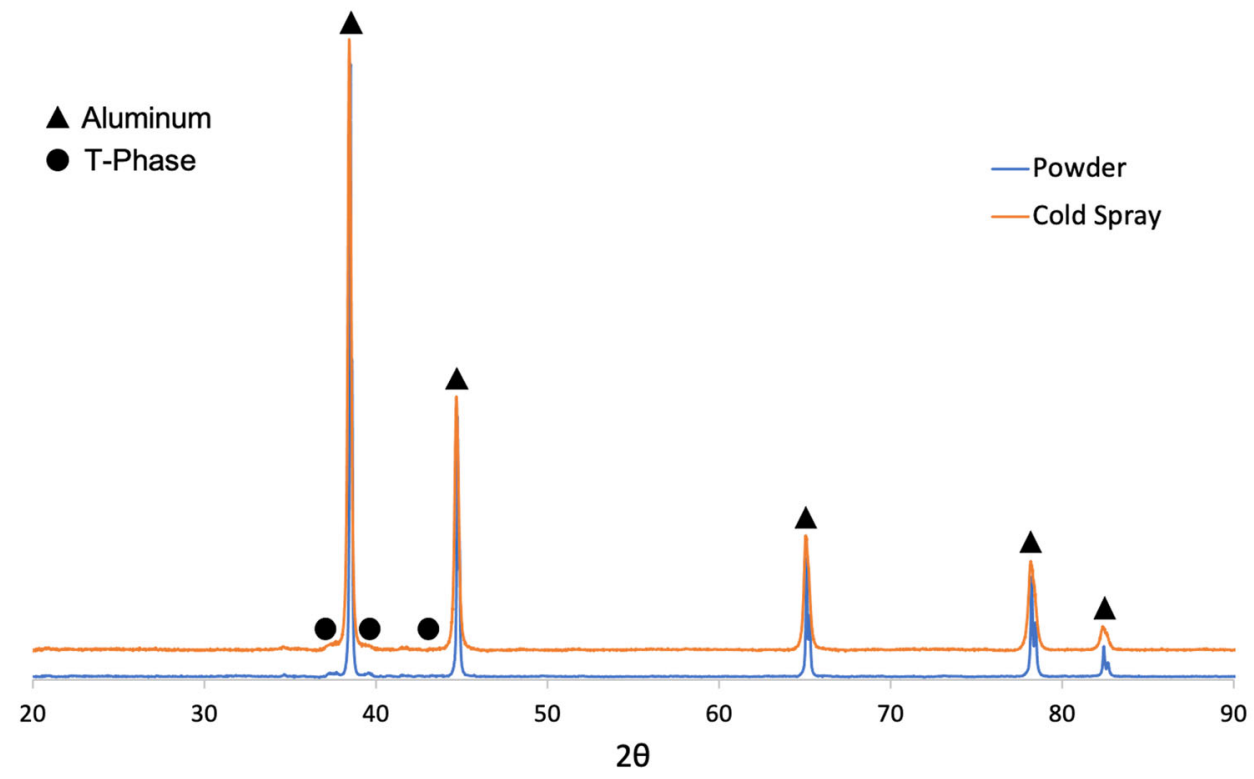

Fig. 5. XRD spectra for Al 7075 powder and CS deposit.

(a) 2.5

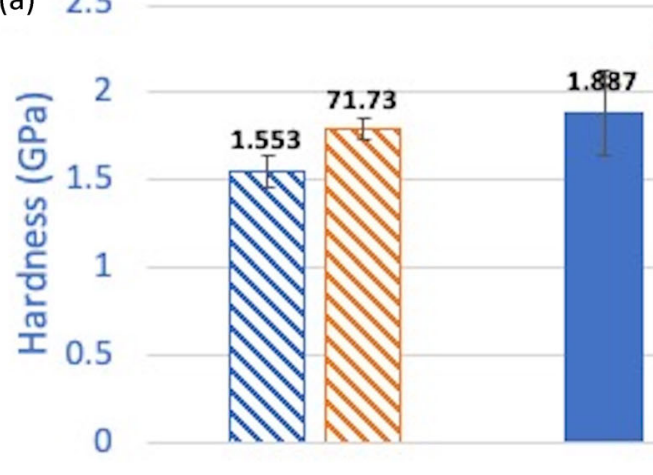

Powder

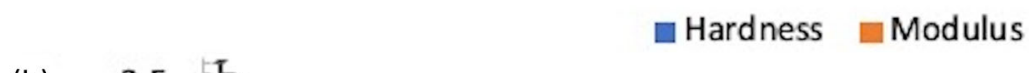

(1)

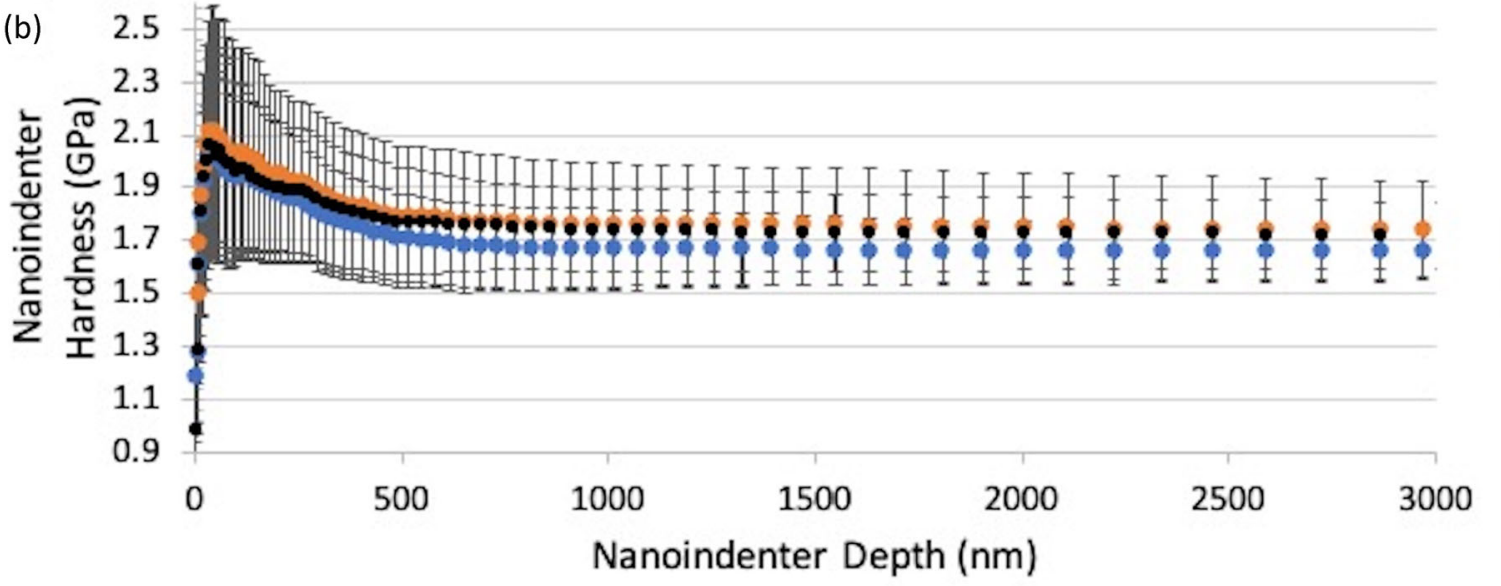

Fig. 6. (a) Average dynamic nanoindentation hardness and modulus of elasticity of the Al 7075 powder and the three orientations of the CS processed consolidations relative to the spray direction. (b) Nano-to-microscale indentation-based hardness vs. depth curves for each of the three orientations of the CS processed consolidations relative to the spray direction. 
failure analysis of the Al 7075 CS consolidations procured herein are presented next.

Figure 7 shows the SEM micrographs and EDS mapping of the CS deposits. Figure 7a and b shows remnants of the retained microstructure of the powder feedstock, which has been severely plastically deformed and refined during powder consolidation. Significant grain recrystallization took place at the outer regions of the deposited particles, which is consistent with prior work aimed at understanding the evolution of microstructures during CSdriven deformation. ${ }^{36}$ Figure $7 \mathrm{c}$ shows the same $\mathrm{Mg}$, $\mathrm{Zn}$, and $\mathrm{Cu}$ present at the grain boundaries, as was seen with the heat-treated feedstock powder. It was also seen that some of the passivating oxide layers on the feedstock powder were retained inside of the CS deposits. The presence of oxide fragments is also consistent with literature concerned with hydrodynamic spallation and oxide/hydroxide fragmentation. However, the degree to which spallation was present raises questions surrounding the conditioning stages employed by the manufacturer.

Figure 5 showed the XRD spectra for the CS deposit compared to the feedstock powder. Again, the same T-phase is seen to be present at similar amounts. Peak broadening was also an indicator of the increased dislocation density due to the high- strain rate particle deformation during the CS process.

Figure 6 shows the nanoindentation results for the feedstock powder compared to the CS deposits. The hardness at $200 \mathrm{~nm}$ of nanoindentation depth was determined in the build (BD), traverse (TD), and stepping directions (SD), at $1.97 \mathrm{GPa}$ in the SDTD orientation, $1.89 \mathrm{GPa}$ in the TD-BD orientation, and $1.87 \mathrm{GPa}$ in the SD-BD orientation, respectively. In that exact order, the modulus of elasticity measured for each orientation was $85.22 \mathrm{GPa}$, 86.88 GPa, and 86.2 GPa. These values show an increase in both hardness and modulus compared to the powder. The increase in the modulus of elasticity may be explained by the degree of increase in the lattice strain due to the severely plastically deformed and work-hardened condition of the CS processed Al 7075. While an increase in hardness relative to the pre-deposited powder was expected and consistent with prior work, the processing parameters and heat-treated condition enabled a much more significant amount of high-strain rate and impact-induced hardening than previously reported for $\mathrm{Al} 7075$ in the as-sprayed and atomized conditions. ${ }^{24}$

Uniaxial tensile testing was conducted to further understand the mechanical properties of the CS
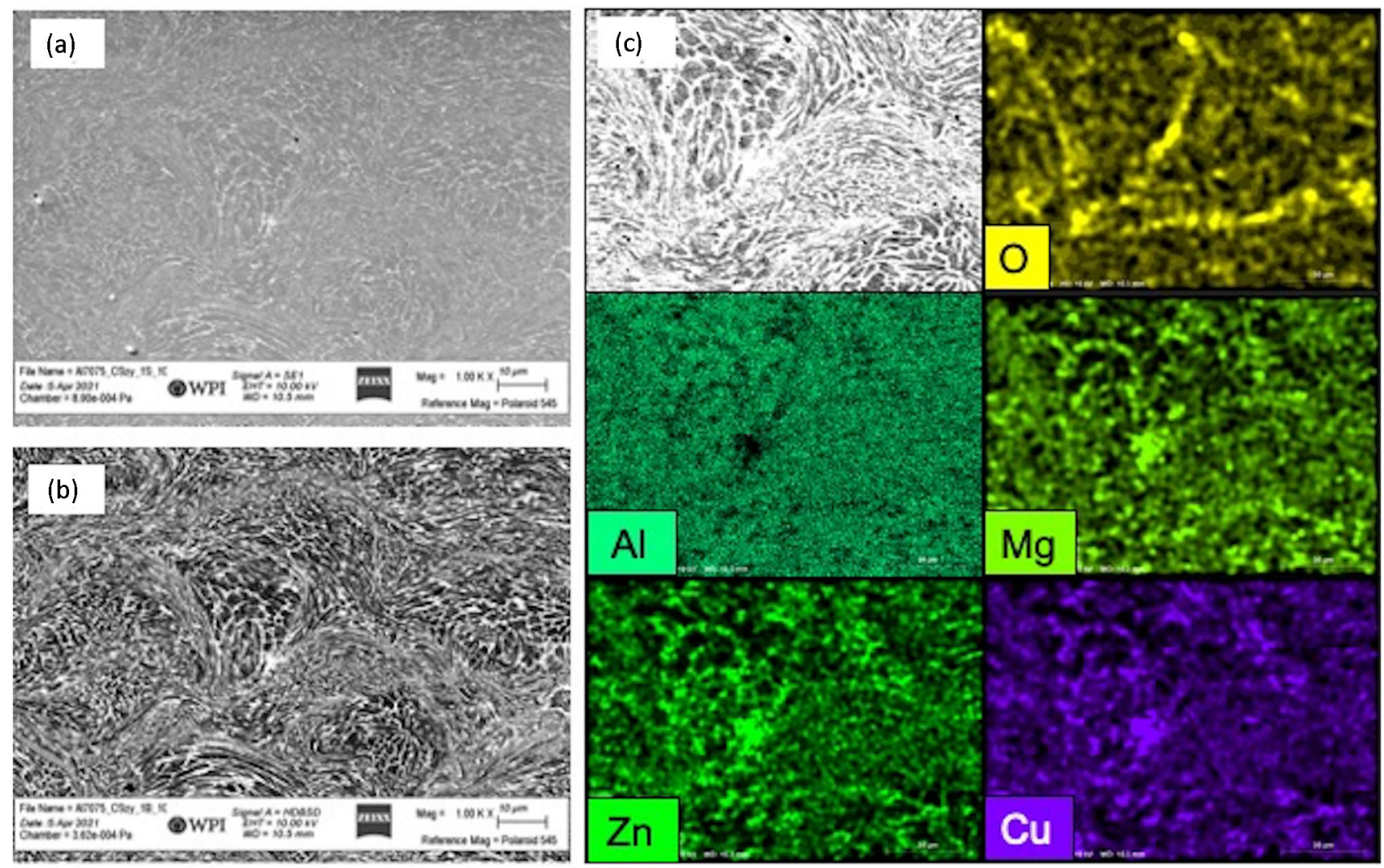

Fig. 7. SEM micrographs of the Al 7075 CS deposit using (a) secondary imaging, (b) backscatter imaging, and (c) EDS elemental mapping for O, $\mathrm{Al}, \mathrm{Mg}, \mathrm{Zn}$, and $\mathrm{Cu}$. 
consolidations and methods of potential failure. The average elongation was $1.61 \%$, with a high of $2.40 \%$ and a low of $1.20 \%$. Yield strength was tabulated to 286.32 $\mathrm{MPa} \pm 20.73 \mathrm{MPa}$. Ultimate tensile strength was inherently low because of the partial/ relatively brittle as-sprayed condition and averaged $357.50 \mathrm{MPa} \pm 20.30 \mathrm{MPa}$. While the mechanical properties associated with a typical 7075-T6 would be significantly higher than the as-sprayed samples herein, the values demonstrated here were comparable to other as-deposited sprays, if not higher in terms of elongation and ultimate tensile strength for $7 \mathrm{xxx}$ CS. This attests to the significance of understanding proper thermal conditioning of feedstock and the implications of thermal treatments on mechanical properties of CS depositions. Understanding the consequences of a thermal pre-process procedure that has not first homogenized and solutionized the feedstock properly before tempering to the desired condition will ultimately enable the presently ongoing research to achieve $\mathrm{Al} 7075$ CS consolidations more readily with structural applicability in engineering applications and ductility closer to those of bulk/wrought and treated $\mathrm{Al}$ 7075 components.

The fracture mechanisms seen in the samples follow a multimodal failure modality with regimes consisting of ductile fracture phenomena and brittle fracture zones, as elucidated in Fig. 8a, b, c, and d. No tensile specimens exhibited visually evident necking, consistent with the brittle mode of failure observed via fractographic analysis of the failed surfaces. However, clear post-yield strain hardening was also present before reaching the material's respective ultimate tensile strength, which compliments the partially ductile mode of failure observed. The figure also presents entrapped particles that affected crack nucleation and propagation, ultimately preventing the attainment of a fully deformed CS condition.

Furthermore, there is evidence of notably large secondary phases along particular regions of the fractured surfaces shown in Fig. 8c and d, which were believed to have exacerbated the multimodal onset of fracture. Analysis of a nanomechanically mapped grid array of the SD-TD specimen orientation confirmed the presence of such a sizeable secondary phase, which was found to occupy at least $0.1 \%$ of the microstructure. The nanomechanical property maps and microstructural feature maps are presented as part of Fig. 8e, f, and g. The nanomechanical mapping and microstructural feature deconvolution via $\mathrm{k}$-means clustering revealed that $20 \%$ of the $\mathrm{CS}$ orientation that underwent the most minor grain refinement was still classified as dynamically recrystallized. In contrast, the remainder was classified as work hardened.

\section{Yield Strength Model and Future Outlook}

To quantify the difference in strength between the feedstock powder and the CS consolidation, an additive yield strength model can be employed to understand the constituents that contribute to the yield strength of both the powder and CS processed materials by way of

$$
\vartheta_{Y S}=\vartheta_{0}+\left(\vartheta_{G S}+\vartheta_{S S}+\vartheta_{P}+\vartheta_{C W}\right)^{\frac{1}{m}}
$$
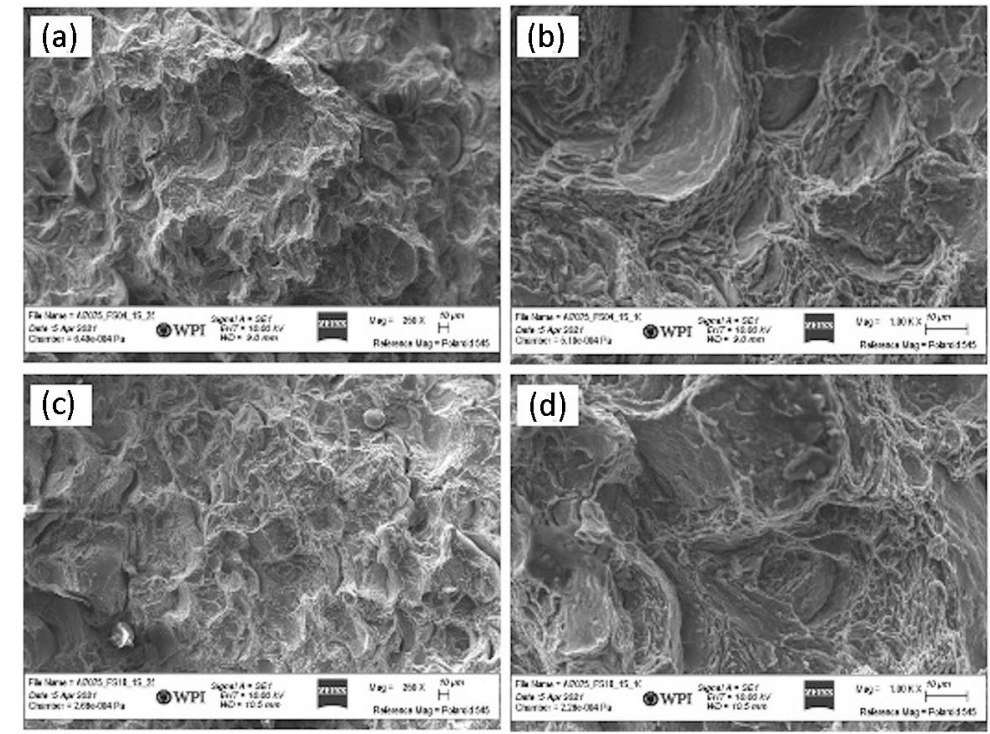
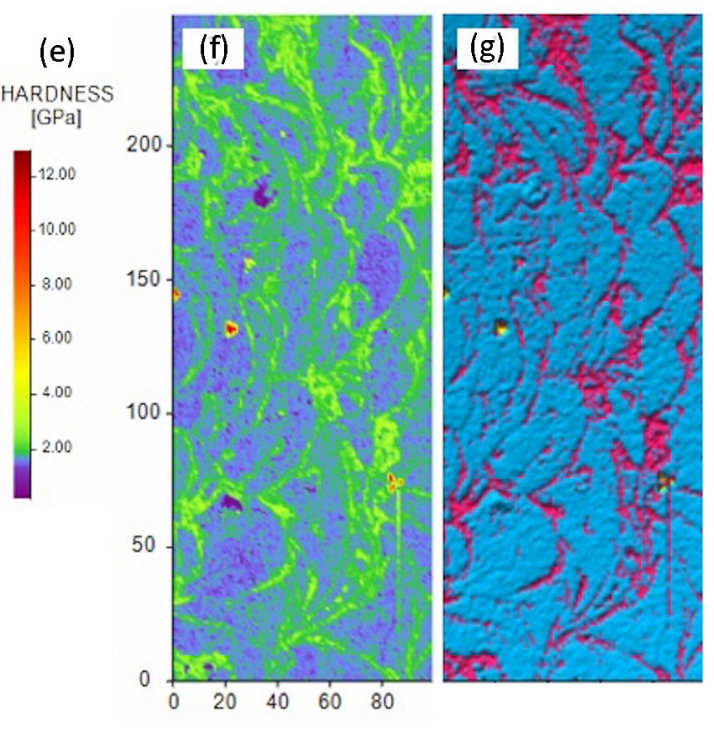

Fig. 8. (a-d) SEM images of the uniaxially tensile tested Al 7075 CS consolidations. (e) Hardness contour plot scale; (f) nanomechanically mapped array of 250-by-100 indents for the SD-TD CS specimen orientation. (g) The k-means clustered and deconvoluted microstructural feature map derived from (f). The yellow feature (hardness of $9.33 \mathrm{GPa} \pm 2.11 \mathrm{GPa})(\mathrm{g}$ ) is a secondary phase. In contrast, the purple region (hardness of $2.35 \mathrm{GPa} \pm 0.33 \mathrm{GPa}$ ) represents severely plastically deformed particle-particle interfaces, and the blue regions (hardness of $1.68 \mathrm{GPa} \pm 0.18 \mathrm{GPa}$ ) represent the interiors of the deposited particles. 
In the additive yield strength expression above, $\vartheta_{0}$ is the intrinsic strength of the material, $\vartheta_{G S}$ is the strength addition from grain size strengthening, $\vartheta_{S S}$ is the strength addition from solid solution strengthening, $\vartheta_{P}$ is the addition from precipitation strengthening, and $\vartheta_{C W}$ is the addition from cold work. For the feedstock powder, it can be assumed that the strength can be calculated via

$$
\vartheta_{Y S}=\vartheta_{0}+\left(\vartheta_{G S}+\vartheta_{S S}+\vartheta_{P}\right)^{\frac{1}{m}}
$$

For the present study, the originally formulated, validated, and verified relation for the strength of a gas-atomized $\mathrm{Al} 7075$ powder was consulted here to establish a baseline determination of an empirically supported model initially developed as part of a thesis on the TPM, ${ }^{37}$ wherein:

$$
\vartheta_{Y S}=\left(H_{v} n^{-1}\right)^{1 / b} \approx \frac{H v}{C\left(40^{n}\right)}
$$

Regarding the baseline formulation provided above, $C$ is a constant that can-depending on the alloy studied-range from 2.9 to 3.3 , as found in Ref. 37 . Meanwhile, the hardness and ultimate tensile strength can be related to the overall yield strength via the assumption of the following stress-strain relation,

$$
\vartheta=B \in^{n},
$$

where $B$ is a constant, $n$ is the work-hardening exponent, and $b$ is an empirically fitted value and alloy-dependent term. That said, the ultimate tensile stress can be defined as

$$
\vartheta_{t}=\vartheta_{Y S}(40)^{n}(1-n)\left(\frac{12.5 n}{1-n}\right)^{n} .
$$

Building upon the approach above, the substitution of the nanoindentation-derived particulate hardness into the yield strength formula yields the following (when the properly determined values of $b$ and $n$ are used for Al 7075), such that:

$$
\begin{aligned}
\vartheta_{Y S} & =\left(H_{v} n^{-1}\right)^{1 / b}=\left(158.1(0.0175)^{-1}\right)^{\frac{1}{1.5392}} \\
& \approx 371.62 \mathrm{MPa} .
\end{aligned}
$$

Given that one may assume that there is no contribution to strength from cold work in the powder when calculating the difference between the strength of the powder and the CS consolidation for these samples, we can assume the following equation:

$$
\Delta \vartheta_{Y S}=\left(\vartheta_{C W}+\vartheta_{G R}\right)^{\frac{1}{m}}
$$

where $\vartheta_{C W}$ is the strength addition from the cold work produced by the CS process, and $\vartheta_{G R}$ is the additional strength added from the refinement of the grains inside the powder microstructure after $\mathrm{CS}$. The yield strength of the powder was calculated to be $371.62 \mathrm{MPa}$, and the yield strength of the CS specimen was calculated to be 406.04 , such that:

$$
\Delta \vartheta_{Y S}=406.04-371.62=34.42=\left(\vartheta_{C W}+\vartheta_{G R}\right)^{\frac{1}{m}}
$$

Upon applying the Nix-Gao strain-gradient plasticity model indentation size effect (ISE) method of determining the hardness at infinite depth to the powder's load-depth data, ${ }^{38}$ the particulate strength was estimated via the use of a Taylor factor to confirm the accuracy of the value just presented. In doing so, the ISE-based yield strength was estimated to be $388.44 \mathrm{MPa}$, which agrees well with the value determined via the hybrid strength model employed above.

Since the nanomechanical mapping unveiled the fact that $20 \%$ of the microstructure underwent dynamic recrystallization, where the average hardness of the recrystallized regions was $2.35 \mathrm{GPa}$, and the average hardness of the cold worked and retained microstructural regions was $1.68 \mathrm{GPa}$, we can therefore work towards quantifying the exact contribution from $\vartheta_{C W}$ and $\vartheta_{G R}$ in follow-on work. Thus, future work will be done to investigate further the strength contributions from cold work and grain refinement within the CS deposits and quantifications from the contributions from strengthening mechanisms associated with the feedstock powder. ${ }^{39}$ Nevertheless, this presently employed JMatPro-based hybrid model provides a foundation that can be built upon and coupled with the robust additive yield strength model and other advanced computational models, such as those presented in Ref. 40.

\section{CONCLUSION}

This work provides an example of a TPE approach to study the relationship between powder properties and consolidated CS behavior through a combined effort of characterization methods and computational modeling. In this study, $\mathrm{Al} 7075$ powder was used as feedstock for the CS process using industrystandard processing parameters. Characterization of the powder using SEM, EDS, and XRD revealed the presence of T-phase in the internal powder microstructure, which was retained during the CS process. In addition, nanoindentation of both the powder and CS deposits revealed an increase in strength after the CS process. This increase in strength can be quantified by the investigation of the CS spray process. Future work will quantify the relationship between the powder and CS properties by evaluating the strengthening mechanism components in the additive yield strength model, including grain size, solid solution strengthening, and precipitation strengthening.

The work lays the foundation for future TPEs, allowing for the systematic isolation of variables that can affect powder and CS properties. While the present study has focused on one powder heat treatment to serve as an example of later TPEs, future studies will systematically review the effects of additional variables, including CS parameters 
(nozzle type, nozzle size, nozzle configuration, gas type, gas temperature, and gas pressure) and powder parameters (powder size, morphology, flowability, chemistry, and heat treatment). In each TPE, only one variable will be studied at a time, as permitted by the strict control of the remaining variables and characterization methods used. Once a variable has been studied, an iterative process can be introduced for the optimization of each parameter to enhance the properties of the final CS coatings.

\section{ACKNOWLEDGEMENTS}

This work was funded by the United States Army Research Laboratory, Grant No. W911NF-19-20108. We express our gratitude to Alino Te, Kevin Thompson, James Walden, and Sean Kelly of Solvus Global for their time and contribution.

\section{CONFLICT OF INTEREST}

The authors declare that they have no conflict of interest.

\section{OPEN ACCESS}

This article is licensed under a Creative Commons Attribution 4.0 International License, which permits use, sharing, adaptation, distribution and reproduction in any medium or format, as long as you give appropriate credit to the original author(s) and the source, provide a link to the Creative Commons licence, and indicate if changes were made. The images or other third party material in this article are included in the article's Creative Commons licence, unless indicated otherwise in a credit line to the material. If material is not included in the article's Creative Commons licence and your intended use is not permitted by statutory regulation or exceeds the permitted use, you will need to obtain permission directly from the copyright holder. To view a copy of this licence, visit http://creativecommons.org/licenses/by/4.0/.

\section{REFERENCES}

1. A. Papyrin, V. Kosarev, S. Klinkov, A. Alkhimov, and V.M. Fomin, in Cold Spray Technology (Elsevier, 2007).

2. C.A. Widener, O.C. Ozdemir, and M. Carter, Procedia Manuf. 21, 361. (2018).

3. M.F. Smith, in The Cold Spray Materials Deposition Process: Fundamentals and Applications (Elsevier, 2007), pp. 43-61.

4. K. Petráčková, J. Kondás, and M. Guagliano, Int. J. Fatigue 110, 144. (2018).

5. J.C. Lee, H.J. Kang, W.S. Chu, and S.H. Ahn, CIRP Ann. Manuf. Technol. 56, 577. (2007).

6. J. Pattison, S. Celotto, R. Morgan, M. Bray, and W. O'Neill, Int. J. Mach. Tools Manuf. 47, 627. (2007).

7. S. Yin, P. Cavaliere, B. Aldwell, R. Jenkins, H. Liao, W. Li, and R. Lupoi, Addit. Manuf. 21, 628. (2018).

8. R. Lupoi, Surf. Eng. 30, 316. (2014).

9. T. Yu, M. Chen, and Z. Wu, Chin. J. Aeronaut. 476, 203581. (2021).

10. Y.K. Wei, X.T. Luo, C.X. Li, and C.J. Li, J. Therm. Spray Technol. 26, 173. (2017).
11. V.K. Champagne, in The Cold Spray Materials Deposition Process: Fundamentals and Applications (Elsevier, 2007), pp. 1-7.

12. A. Papyrin, in The Cold Spray Materials Deposition Process: Fundamentals and Applications (Elsevier, 2007), pp. 11-42.

13. M. Dixit, R.S. Mishra, and K.K. Sankaran, Mater. Sci. Eng., A 478, 163. (2008).

14. E. Irissou, and B. Arsenault, Coating 549, 661. (2007).

15. V.K. Champagne, J. Fail. Anal. Prev. 8, 164. (2008).

16. V.K. Champagne, in The Cold Spray Materials Deposition Process: Fundamentals and Applications (Elsevier, 2007), pp. 327-352.

17. Y. Rao, Q. Wang, D. Oka, and C.S. Ramachandran, Surf. Coat.Technol. 383, 125271. (2020).

18. P. Cavaliere, and A. Silvello, J. Therm. Spray Technol. 26, 661. (2017).

19. B.C. Sousa, C. Walde, V.K. Champagne, A.T. Nardi, R.D. Sisson, and D.L. Cote, Coatings 10, 1. (2020).

20. F.J. Brodmann, in The Cold Spray Materials Deposition Process: Fundamentals and Applications (Elsevier, 2007), pp. $105-116$.

21. A. Nastic, D. MacDonald, and B. Jodoin, pp. 33-85 (2020).

22. C. Massar, K. Tsaknopoulos, B.C. Sousa, J. Grubbs, and D.L. Cote, JOM 72, 3080. (2020).

23. R. Ghelichi, S. Bagherifard, D. Macdonald, I. FernandezPariente, B. Jodoin, and M. Guagliano, Appl. Surf. Sci. 288, 26. (2014).

24. B.C. Sousa, M.A. Gleason, B. Haddad, V.K. Champagne, A.T. Nardi, and D.L. Cote, Metals 10, 1. (2020).

25. ASTM Standard E8/E8M-21, in Standard Test Methods for Tension Testing of Metallic Materials (West Conshohocken, PA, 2021).

26. R. Valente, A. Ostapenko, B.C. Sousa, J. Grubbs, C.J. Massar, D.L. Cote, and R. Neamtu, in 2020 IEEE International Conference on Big Data (Big Data) (IEEE, 2021), pp. 2919-2928.

27. O. Molnárová, P. Málek, F. Lukáč, and T. Chráska, Materials 9 , 1004. (2016).

28. C. Walde, K. Tsaknopoulos, V. Champagne, and D. Cote, Metallogr. Microstruct. Anal. 9, 419. (2020).

29. Q. Wang, Z. Zhao, Y. Zhao, K. Yan, C. Liu, and H. Zhang, Mater. Des. 102, 91. (2016).

30. K. Tsaknopoulos, C. Walde, V. Champagne, and D. Cote, JOM 71, 435. (2019).

31. C. Walde, K. Tsaknopoulos, V. Champagne, and D. Cote, Metallogr. Microstruct. Anal. 8, 415. (2019).

32. C. Walde, D. Cote, V. Champagne, and R. Sisson, J. Mater. Eng. Perform. 28, 601. (2019).

33. F. Meng, D. Hu, Y. Gao, S. Yue, and J. Song, Mater. Des. 109, 503. (2016)

34. A. Sabard, P. McNutt, H. Begg, and T. Hussain, Surf. Coat. Technol. 385, 125367. (2020).

35. W.A. Story, in Processing-Microstructure-Property Relations in High Pressure Cold Spray of AA2024 and AA7075, University of Alabama (2018).

36. B.C. Sousa, C.E. Walde, V.K. Champagne Jr., and D.L. Cote, Int. J. Metall. Met. Phys. 5, 50. (2020).

37. D. Belsito, in Application of Computational Thermodynamic and Solidification Kinetics to Cold Sprayable Powder Alloy Design, Worcester Polytechnic Institute (2014).

38. W.D. Nix, and H. Gao, J. Mech. Phys. Solids 46, 411. (1998).

39. D. Tsaknopoulos, in Optimization of Coupled Computational Modeling and Experimentation for Metallic Systems: Systematic Microstructural Feature-Mechanical Property Correlation for Cold-Sprayable Powders, Worcester Polytechnic Institute (2019).

40. Q. Wang, N. Ma, M. Takahashi, X. Luo, and C. Li, Acta Mater. 199, 326. (2020).

Publisher's Note Springer Nature remains neutral with regard to jurisdictional claims in published maps and institutional affiliations. 